\title{
A conversation with Griffin Rodgers
}

B eginning in the mid-1980s, Dr. Griffin Rodgers, Director of the National Institute of Diabetes and Digestive and Kidney Diseases (NIDDK) at the National Institutes of Health, led studies demonstrating the effectiveness of the drug hydroxyurea, the first FDA-approved drug for sickle cell disease. Since then, Rodgers (Figure 1) has worked on transplant strategies and therapies for sickle cell disease and other hemoglobinopathies while also taking on massive leadership and administrative roles at the NIH, culminating in his appointment to the directorship of the NIDDK in 2007. See the JCI website (https://www.jci.org/ videos/cgms) to hear about how Malcolm Gladwell and Howard Hughes played a role in sickle cell anemia and why it's fitting to study hematology at a diabetes- and kidney-focused institute.

JCI: Can we hear a little about your family and what you were like as a kid?

Rodgers: I was born and raised in New Orleans, Louisiana. I went to school in the sixties and seventies. My mother was a public health nurse, and my father was a high school science and public health teacher. And as a kid, I was studious. I wasn't very tall, and therefore I gravitated towards academic sports. But specifically, my interests really focused on math and science, areas that I had an affinity for. At an early age, I sealed my interest in medicine. During my early years in grammar school, my mother, who I mentioned was a public health nurse, would often have me accompany her on the weekends when she went to people's homes who couldn't get into the clinics during the regular week to receive their vaccinations and other medicine. It was probably that period that solidified my great interest in going into medicine. These were often very poor, impoverished neighborhoods, often housing projects; the health disparities were very prevalent in New Orleans. One could clearly see the role that poverty had in really making these common chronic diseases more prevalent and much more serious.

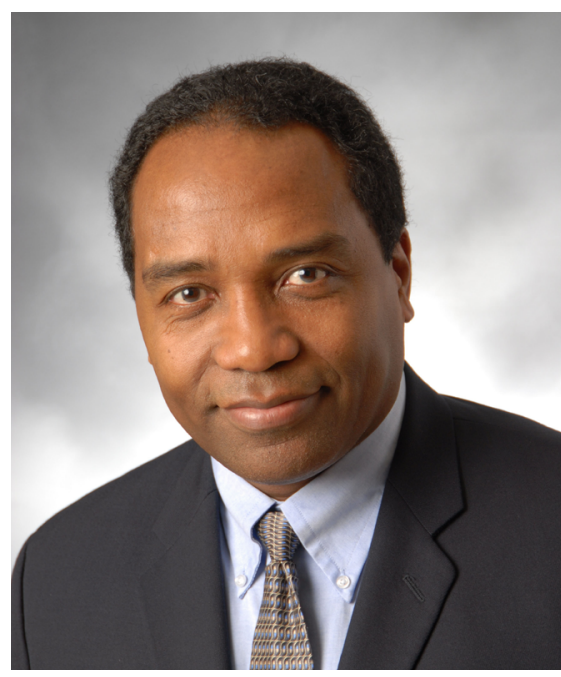

Figure 1. Griffin Rodgers. Image credit: National Institutes of Health.

JCI: You've spoken about three friends in high school who all had sickle cell disease. I imagine that that must have had a massive impact on you.

Rodgers: By the time I'd gotten to high school, I was clearly drawn to the area of medicine. I went to an all-boys school, but had these three friends at other high schools throughout the city. All three friends had sickle cell disease, and at that time, there was very little that you could do. If they were in pain, you would give them pain medicines, if their blood counts got too low, you would give them blood transfusions, and if they had an infection, antibiotics. But beyond that, there was very little that you can do. The life expectancy at that time didn't exceed the mid-20s.

One of these friends died when I was still in high school, and two others died while I was attending college. Watching them suffer and die probably did instill in me a desire to learn more about the disease and ultimately led to my decision to go into the field of hematology and carry out biomedical research in sickle cell disease.

I applied to colleges where I could accelerate my movement from undergraduate to medical school, which ultimately led me to select just a few schools to apply to.
Ultimately, I was accepted to the program at Brown University; from high school, I was accepted into not only the college, but also into their advanced medical program.

$J C I:$ Were you able to get any research experience during this time?

Rodgers: We were all assigned a professional mentor, and since I was in this advanced medical program, I was fortunate to have Dr. Pierre Galletti, who was the equivalent of the dean of the medical school, as my mentor. He was a very wellknown bioengineer. At the time, he had developed both an artificial kidney and an artificial lung, and he actually had sort of a merger of those two that he called the klung. It was my assignment to study various parameters of the blood before it went into this device and then after it came out, particularly how well the kidney was filtering the blood and how well the lung was oxygenating the blood.

Later, as I affirmed my goal to work on sickle cell, I had thought I could team up with one of the chiefs of medicine at one of the affiliated hospitals in the field of sickle cell disease, but it turns out that there weren't very many African-American individuals [in whom sickle cell disease happens more frequently] in Rhode Island or neighboring areas. We instead chose to work in the field of red blood cell metabolism among octogenarians. There was really no shortage of octogenarians in Rhode Island at the time! Our goal was to determine whether the red cell, being a terminally differentiated cell, could give some clue as to the overall aging process within the body. That work gave me the ability to master rigor and reproducibility in my techniques.

JCI: What made you choose Washington University for your residency?

Rodgers: They were very well known for internal medicine; I was really looking to get an outstanding training in the field of internal medicine and possibly staying there to continue on with the hematology fellowship. At Wash U, I met some very talented professors, some of whom you've actually interviewed on this series, and they really further inspired my desire to go into research.

JCI: After your internship, residency, and chief residency, how did you end up 
at the NIH? And especially for someone interested in hematology, how did you end up at the NIDDK?

Rodgers: Let me just go back a little bit to Wash $\mathrm{U}$ to tell you about some of those connections. One of my mentors at Wash U was Dr. Jim Gavin, who worked with Dr. Jesse Roth, who I know you've interviewed in this series. Dr. Gavin was involved in the identification of the insulin receptor early on after he received his $\mathrm{PhD}$. He strongly recommended that I consider not only going to the NIH, but actually working in what was the "precursor institute" of the NIDDK at the time. And then when I became a senior resident at the NIH, I was chosen to be a chief resident at the affiliated John Cochran VA Hospital. The chief of medicine there was a fellow named Lewis Chase, who, as it turns out, was an endocrinologist who had also worked at the NIDDK. He also strongly encouraged me to consider a fellowship at the NIH - within the NIDDK.

At the time, I said, "If I'm interested in sickle cell disease, why would I be going to the diabetes institute?" They knew of my interest, so the mentor at NIH with whom I was assigned to work was Dr. Alan Schechter, who had just published a paper in the New England Journal of Medicine on sickle cell disease summarizing the pathophysiology and potential therapies as they understood it in the mid to late '70s.

JCI: How did you get involved in some of the early studies on the molecular genetics of hemoglobinopathies, and then what led you to lead the clinical trials on hydroxyurea for sickle cell disease?

Rodgers: Schechter and colleagues, including Dr. Connie Noguchi, had been working on the concept that in sickle cell disease, it's not the sickling of the cell per se that leads to the pathology, but the biophysical state of the hemoglobin inside the cell that dictates the pathophysiology. Normal hemoglobin, which can reversibly bind oxygen and carbon dioxide, continues to be soluble in solution inside cells, but also in free solution outside of erythrocytes. Because of the mutation in sickle cell disease, when the hemoglobin tetramers give up their oxygen, they undergo this physical, structural change in their three-dimensional geometry, and they become sticky. They form a polymer with adjacent hemoglobin molecules. These strands form large polymers inside the cell, which, if the cell was able to get back to the lungs and get reoxygenated, the polymer melts away. But some of the polymer remains inside the cells, making them less deformable, which they have to be once they get into the small capillaries.

It was Schechter and Noguchi's view, as well as others', that if you could somehow inhibit this fundamental polymerization process, irrespective of whether the cells look sickle or not, you could restore the normal rheology of the cell.

We also learned clinically that young children did not display their first symptoms of sickle cell disease until they're six to nine months of age. The delay is because a second type of hemoglobin predominates during the second and third trimester in utero, so-called fetal hemoglobin. Based upon these structural studies, we knew that the fetal hemoglobin molecule can interact with the polymer and melt it away. And in fact, in populations that maintained a persistently high level of fetal hemoglobin even in adulthood, these patients tend to have mild, almost inconsequential disease. Studying those with high fetal hemoglobin led to the belief that if you could somehow stimulate fetal hemoglobin production to a certain degree to replicate what you see in those populations, one could possibly nearly erase the clinical disease.

Additionally, a lot of work went into using the drug hydroxyurea to treat patients who had other types of myeloproliferative diseases, like chronic myelogenous leukemia or polycythemia vera. Most of them showed a small, albeit significant, rise in the fetal hemoglobin levels once hydroxyurea was administered. All these facts converged to lead us to develop this clinical study at the NIH Clinical Center, hospitalizing sickle cell patients for about three months to follow the effects of treatment with hydroxyurea. We measured about a $70 \%$ clinical response rate, which was confirmed in subsequent patients with whom we achieved a similar result.

It was very exciting. People say that you first start a project and if that project gets successful, it turns into a program. The key to the success of that program really rests upon the direction that you go in and in the people that you're able to recruit into your program. I think I was successful in both. I was able to move the program of developing successful therapies for people with sickle cell disease, and that ultimately led to its replication in other sites, eventually with the [National] Heart, Lung and Blood Institute funding a large randomized controlled trial which ultimately led to the drug being the first FDA-approved drug in adults. Subsequently, additional studies led to its extension of the drug in children and adolescents.

JCI: You moved from fellow to investigator to deputy director to acting director and then, in 2007, the director of the NIDDK. Why have you stayed this long?

Rodgers: These types of positions come up very rarely. I think one has to prepare themselves for it. It is said that, for example, a physician in the course of their career might affect the lives of a few thousand patients by seeing them in their office or in their clinic. If you're a teacher of medicine, it has a multiplying effect because of the hundreds in each class. Over the course of a medical career, you could potentially affect, indirectly, the lives of 100,000 patients. But if you're a researcher or an administrator of that research, a conduit and a support for the research, you potentially have a mark on millions, perhaps tens of millions of people, worldwide. You really can't turn that type of opportunity down.

I've been very pleased to be at the NIDDK for these many years, both initially as a fellow and then ultimately as an administrator because, by the way, you don't need to necessarily give up anything. I still see patients occasionally, I run a research laboratory, and I also have a chance to support and conduct research on what I think are some of the nation's most common and chronic and costly and consequential diseases. And that's really what keeps me excited.

JCI: What other profession could you have possibly pursued that would have kept you this dedicated?

Rodgers: I enjoy what I'm doing now so much that I'd be hard-pressed to give you a second alternative. When you're doing what you truly love and you actually get paid for it, you can't ask for anything better. I think, fundamentally, people that are interested in math and science are, almost by definition, educators. So, I guess if there was an alternative path that I would have taken, it would have been in math or science education.

Ushma S. Neill 